\title{
Síntese e caracterização de arcabouços de quitosana com agente antineoplásicos
}

\author{
Synthesis and characterization of chitosan \\ scaffolds with antineoplastic agent
}

Jackson Borba da Cruz ${ }^{1}$, Carmem Dolores de Sá Catão ${ }^{1}$, Rossenberg Cardoso Barbosa ${ }^{2}$, Marcus Vinicius Lia Fook ${ }^{2}$

\author{
${ }^{1}$ Unidade Acadêmica de Ciências Médicas - UACM/UFCG - CEP: 58429-600, Campina Grande, PB. \\ e-mail: jacksonborba3@gmail.com; sacatao@ig.com.br \\ ${ }^{2}$ Laboratório de Avaliação e Desenvolvimento de Biomateriais do Nordeste - CERTBIO/UFCG - CEP: 58429-900, \\ Campina Grande, PB \\ e-mail: rcbvet@gmail.com; marcusvinicius@dema.ufcg.edu.br
}

\section{RESUMO}

O sistema de liberação controlada de fármacos através da utilização de biomateriais poliméricos associados a compostos com ação antineoplásica pode ser empregado como alternativa de tratamento de neoplasias. Desta forma, este trabalho teve como objetivo a síntese e caracterização de sistemas de arcabouços de quitosana com o agente antineoplásico (1,4-naftoquinona), cuja taxa de liberação pode ser controlada pela utilização de um agente reticulante como o tripolifosfato de sódio (TPP). O método de preparação consistiu da solubilização da quitosana em ácido acético, adição do fármaco, congelamento, liofilização e reticulação com TPP. Todas as amostras foram caracterizadas por Difração de Raios X (DRX), Microscopia Eletrônica de Varredura (MEV), Espectroscopia de Energia Dispersiva de Raios X(EDS), grau de intumescimento e biodegradação enzimática. Na MEV foi evidenciada a formação de poros interconectados com tamanhos e formas variadas em todas as estruturas estudadas caracterizando a formação de arcabouços. Já no EDS foi observada a presença de elementos químicos característico da composição química de cada material. No entanto foi observada a presença do sódio que pode estar relacionado ao agente neutralizante utilizado. A reticulação de parte dos arcabouços foi comprovada pelo DRX, EDS e aumentou a taxa de degradação enzimática in vitro dos mesmos. A incorporação do fármaco foi confirmada por DRX, grau de intumescimento e EDS. Desta forma, pode-se concluir que ocorreu à formação de arcabouços reticulados e não reticulados porosos, com propriedades morfológicas e físico-químicas que podem contribuir para carrear fármacos antineoplásicos, sendo possível controlar a taxa de degradação dos mesmos e provável liberação do fármaco.

Palavras chaves: Quitosana, Neoplasia, Reticulação, Arcabouços.

\section{ABSTRACT}

The controlled release system of drugs through the use of polymeric biomaterials compounds associated with antineoplastic action can be employed as an alternative treatment of neoplasms. Thus, this study had as objective the synthesis and characterization of the systems of scaffolds of chitosan loaded with the antineoplastic agent (1,4-naphthoquinone), whose release rate can be controlled by using a crosslinking agent such as sodium tripolyphosphate (TPP). The preparation method consisted of solubilizing the chitosan in acetic acid, drug addition, freezing, lyophilization and crosslinking TPP. All samples were characterized by X-Ray Diffraction (XRD), scanning electron microscopy (SEM), Energy Dispersive X-ray Spectroscopy (EDS), degree of swelling and enzymatic biodegradation. SEM showed the formation of interconnected pores with varying shapes and sizes in all the studied structures characterizing the formation of scaffolds. In EDS the presence of chemical elements characteristic of the chemical composition of each material was observed. However, the presence of sodium was observed which can be related to the neutralization agent used. The crosslinking of the scaffolds was confirmed by XRD and EDS which increased the enzymatic degradation rate in vitro in the same sample. The incorporation of the drug was confirmed by XRD, degree of swelling and EDS. Thus, it can be concluded that occurred the formation of crosslinked and non-crosslinked porous 
scaffolds with morphological and physicochemical properties that can contribute to the carrying of antineoplastic drugs, being possible to control the degradation rate thereof and probable the release of the drug.

Keywords: Chitosan, Neoplasia, Crosslinked, Scaffold.

\section{INTRODUÇÃO}

Dentre os polímeros utilizados na produção de estruturas porosas, a quitosana se destaca devido a suas características de biocompatibilidade, biodegradabilidade e biofuncionalidade. A quitosana é um polissacarídeo derivado da desacetilação parcial da quitina. Quimicamente, quitina e quitosana estão proximamente relacionadas onde ambas são polissacarídeos lineares contendo as unidades 2-acetamido-2-desoxi-D-glicopiranose (GlcNAc) e 2-amino-2-desoxi-D-glicopiranose $(\mathrm{GlcN})$ unidas por ligações glicosídicas do tipo $\beta(1 \rightarrow 4)$. A diferença entre elas está no grau de acetilação (GA), que corresponde a proporção de unidades GlcNAc em relação às de GlcN, e na solubilidade em meio ácido. A quitina possui um GA > 0,5 e é insolúvel em meio ácido. A quitosana é solúvel em meio ácido e possui $\mathrm{GA} \leq 0,5[1,5]$.

Neoplasia $($ neo $=$ novo + plasia $=$ formação), também conhecida como tumor, designa uma proliferação anormal de células sem um objetivo definido, sem controle fisiológico, persistente e com efeitos agressivos ao organismo. Decorre de alterações genéticas que controlam o crescimento, a diferenciação, reparação do DNA e apoptose. As células neoplásicas apresentam diferenciação variável e, no caso das malignas, podem determinar a formação de tumores à distância independentes e descontínuos em relação ao tumor primário. Há basicamente dois tipos de tumores: benignos e malignos (câncer) [6].

Desta forma, torna-se imprescindível o estudo e desenvolvimento de alternativas terapêuticas de combate ao câncer, seja no campo preventivo, bem como no diagnóstico e tratamento precoces. Assim, neste trabalho, foram desenvolvidos arcabouços de quitosana associados a 1,4-naftoquinona (molécula bioativa com ação antitumoral) e avaliados quanto às características físico-químicas e biodegradação, buscando, possivelmente, o desenvolvimento de sistemas de liberação controlada de fármacos para o combate ao câncer, possibilitando relevantes benefícios à população acometida com a referida patologia.

\section{MATERIAIS E MÉTODOS}

A pesquisa foi desenvolvida no Laboratório de Avaliação e Desenvolvimento de Biomateriais do Nordeste (CERTBIO) - UFCG/UAEMa.

\subsection{Reagentes Utilizados}

- Ácido Acético Glacial $\left(\mathrm{C}_{2} \mathrm{H}_{4} \mathrm{O}_{2}\right)$ - Vetec ${ }^{\circledR}$ Química Fina Ltda com grau analítico;

- Hidróxido de Sódio $(\mathrm{NaOH})$ - Vetec ${ }^{\circledR}$ química Fina Ltda com grau analítico;

- Tripolfosfato de sódio $\left(\mathrm{Na}_{5} \mathrm{O}_{10} \mathrm{P}_{3}\right)$ - Sigma Aldrich ${ }^{\circledR}$;

- $\quad$ Phosphate Buffered Saline (PBS) - Sigma Aldrich ${ }^{8}, \mathrm{pH}=7,4$;

- Quitosana de médio peso molecular- Sigma Aldrich ${ }^{\circledR}$ - Grau de desacetilação de 75-85\%

- 1,4-naftoquinona $\left(\mathrm{C}_{10} \mathrm{H}_{6} \mathrm{O}_{2}\right)$ - Sigma Aldrich ${ }^{\circledR}$;

- $\quad$ Lisozima - Sigma Aldrich ${ }^{\circledR}$.

\subsection{Método}

\subsubsection{Preparação das soluções de quitosana e quitosana com 1,4-naftoquinona}

A solução de quitosana $2 \%(\mathrm{~m} / \mathrm{v})$ foi preparada através da dissolução do polímero em ácido acético a $1 \%$ (v/v), sob agitação mecânica durante 24h a 410 rpm com pH final 4,7. Para obtenção da solução com o fármaco, foi adicionado $0,047 \mathrm{~g}$ de 1,4 -naftoquinona à solução de quitosana a fim de obter uma concentração final de $300 \mu \mathrm{M}$, concentração efetiva contra células de câncer de cólon [4], do fármaco. A solução também foi mantida sob agitação pelo mesmo intervalo de tempo e número de rotações. Na Figura 1, observa-se o aspecto final das soluções. 


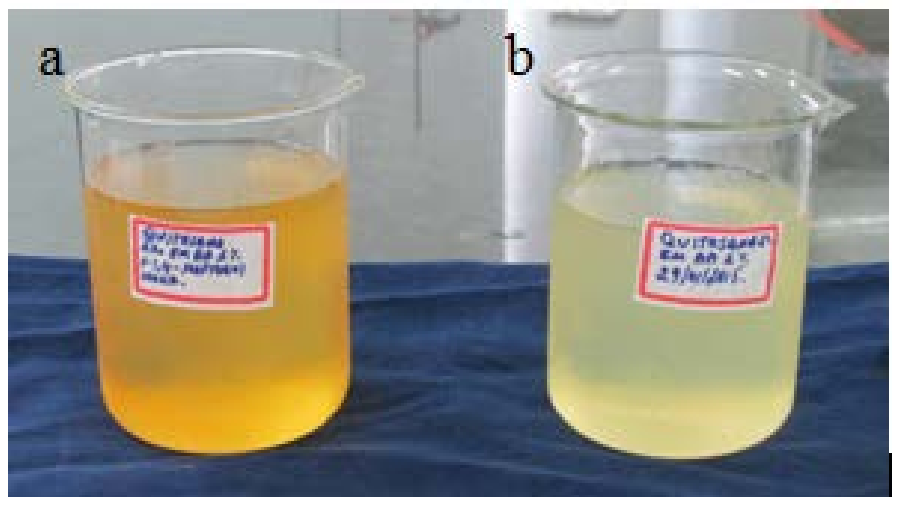

Figura 1: Solução de quitosana com 1,4-naftoquinona (a) e quitosana (b)

\subsubsection{Preparação dos arcabouços de quitosana}

Os arcabouços de quitosana foram confeccionados por liofilização, processo em que a água passa diretamente do estado sólido para o gasoso (sublimação). Para tanto, placas de Petri de acrílico com 57,47 mm de diâmetro, 13,42 $\mathrm{mm}$ de altura e capacidade de $30 \mathrm{ml}$ foram preenchidas com solução de quitosana, acondicionadas no ultra-freezer $\left(-70^{\circ} \mathrm{C}\right)$ por $24 \mathrm{~h}$ para congelamento e, posteriormente, transferidas para o liofilizador onde permaneceram por um período de 72h. Após a liofilização, os arcabouços formados foram neutralizados parcialmente (pH entre 6 e 6,5) pela imersão em solução de hidróxido de sódio 1 M por 30 minutos (Figura 2), seguidas de diversas lavagens com água destilada até atingir o pH descrito acima com o objetivo de manter um maior número de grupos NH2 protonados, já que o pKa dos grupos amino nas unidades GlcN está em torno de 7,2. As medidas do $\mathrm{pH}$ foram realizadas em um pHmetro digital da marca Quimis® previamente calibrado com as soluções padrão. Uma vez ajustado o pH, os moldes (placas de Petri com volume de $30 \mathrm{ml}$ ) tinham os espaços remanescentes, entre a placa e o arcabouço, preenchidos com água destilada e acondicionados no ultra-freezer com temperatura de $-70^{\circ} \mathrm{C}$ por 24 horas. Após este período, as placas foram colocadas no liofilizador por 72 horas.

\subsubsection{Preparação dos arcabouços de quitosana com 1,4-naftoquinona}

Neste caso, o procedimento foi o mesmo do descrito no item 2.2.2, utilizando, porém, a solução de quitosana com o fármaco.

\subsubsection{Preparação dos arcabouços de quitosana e quitosana /1,4-naftoquinona reticulados com tripoli- fosfato de sódio (TPP)}

Os arcabouços reticuladas com TPP obtidas nesta pesquisa seguiram a mesma metodologia de preparação e neutralização parcial dos arcabouços de quitosana e quitosana com 1,4-naftoquinona já descritos acima, diferindo apenas na substituição do hidróxido de sódio pela solução de tripolifosfato de sódio 2\% (m/v), pH 8,5. (Figura 2).

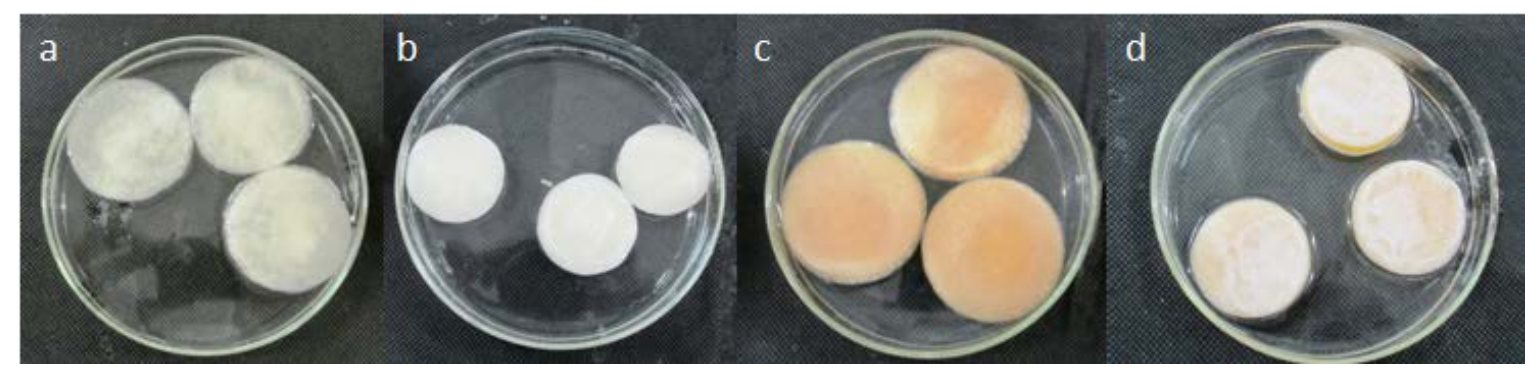

Figura 2: Processo de neutralização parcial dos arcabouços de quitosana (a), quitosana e TPP (b), quitosana e 1,4naftoquinona (c) e quitosana, 1,4-naftoquinona e TPP (d). 
A Tabela 1 ilustra a identificação dos arcabouços preparados nesse trabalho.

Tabela 1: Identificação dos arcabouços confeccionados

\begin{tabular}{l|l}
\hline ARCABOUÇO & IDENTIFICAÇÃO \\
\hline Quitosana & Q \\
\hline Quitosana + TPP & QT \\
\hline Quitosana + 1,4-Naftoquinona & QN \\
\hline Quitosana + 1,4-Naftoquinona + TPP & QNT \\
\hline
\end{tabular}

\subsubsection{Determinação da densidade dos arcabouços}

O cálculo do volume $\left(\mathrm{cm}^{3}\right)$ e densidade $\left(\mathrm{g} / \mathrm{cm}^{3}\right)$ dos arcabouços foi determinado a partir da média de 15 medidas, utilizando paquímetro digital com escala em milímetros, dos diâmetros (mm), espessuras (mm) e massas (g) dos arcabouços, utilizando as equações abaixo:

$$
V=\pi r^{2} \times h
$$

Onde: $V=$ Volume, $\pi=$ raio e $h=$ espessura.

$$
D=\frac{m}{v}
$$

Onde: $D=$ densidade, $m=$ massa, $v=$ volume.

\subsubsection{Técnicas de caracterização}

Todas as amostras foram caracterizadas por Difração de Raios X (DRX) utilizando um difratômetro SHIMADZU (modelo XRD 6000) com varredura angular de $5^{\circ}$ a $40^{\circ}$ com passo de $1^{\circ} / \mathrm{min}$, na montagem de Bragg-Brentano, sistema $\theta-2 \theta$, utilizando radiação $\mathrm{CuK} \alpha$ na tensão de $40 \mathrm{KV}$ e corrente de $30 \mathrm{~mA}$; Microscopia Eletrônica de Varredura (MEV), utilizando-se um microscópio eletrônico de varredura de bancada, modelo TM-1000, marca Hitachi, com aumentos de 500x, profundidade de foco de 1mm, resolução de 30nm, $15 \mathrm{KV}$, sem recobrimento metálico, mesmo em amostras não condutoras; Espectroscopia de Energia Dispersiva de Raios X(EDS) com detector acoplado ao MEV de bancada, modelo TM-1000 da marca Hitachi; grau de intumescimento e biodegradação enzimática.

Para determinação do grau de intumescimento, foram cortados, com auxílio de bisturi, 10 cubos com aresta de $0,5 \mathrm{~cm}$ (medidos com a utilização de um paquímetro digital com escala em $\mathrm{mm}$ ) dos arcabouços de Q, QT, QN e QNT. Cada cubo, com área de superfície de $1,5 \mathrm{~cm}^{2}$ e volume de $0,125 \mathrm{~cm}^{3}$ foi pesado em balança analítica digital antes da imersão em solução de PBS (Phosphate Buffered Saline). Posteriormente, os cubos foram imersos em solução de PBS por um período de 24h. Em sequência, foram removidos da solução e o peso úmido de cada fragmento foi medido na mesma balança. O cálculo do grau de intumescimento (em percentagem) foi realizado segundo a seguinte equação:

$$
G I \%=\left(\frac{M_{i}-M_{0}}{M_{0}}\right) \times 100
$$

Onde: $G I \%=$ Grau de intumescimento em percentagem, $M_{i}-$ Massa intumescida, $M_{0}-$ Massa seca.

O ensaio de biodegradação enzimática foi realizado com base nas normas ASTM F1635-04 Standard Test Method for in vitro Degradation Testing of Hydrolytically Degradable Polymer Resins and Fabricated Forms for Surgical Implants (2009) [19] e a ASTM F2103-01 Standard Guide for Characterization and Testing of Chitosan Salts as Starting Materials Intended for Use in Biomedical and Tissue-Engineered Medical Products Applications (2007) [20].

Para realização desse ensaio, foram preparadas 120 amostras (com geometria cúbica de 0,5 cm de aresta, área de superfície de $1,5 \mathrm{~cm}^{2}$ e volume de $0,125 \mathrm{~cm}^{3}$ ) dos arcabouços de Q, QT, QN e QNT, divididas em 03 grupos de 40 amostras, para submersão em PBS (constituída por NaCl, KCl, Na2HPO4 e KH2PO4 ou NaH2PO4) e PBS/lisozima (concentração de 1,5 mg/ml da enzima) durante 7, 14 e 21 dias (Tabela 2), buscando reproduzir ciclos semanais de quimioterapia no tratamento do câncer. Assim, 60 amostras foram imersas em PBS e 60 em PBS/lisozima. Antes da imersão, os cubos foram pesados em balança analítica, imersos 
na solução e colocados na estufa a $37^{\circ} \mathrm{C}$. Ao final de 7 dias, o $1^{\circ}$ grupo foi removido da estufa, lavado em água destilada, congelado no ultra freezer a $-70^{\circ} \mathrm{C}$, liofilizado por $72 \mathrm{~h}$ e novamente pesados. No segundo e terceiro grupos, as soluções de PBS e PBS/lisozima foram trocadas por novas soluções com a mesma composição e novamente acondicionados na estufa à mesma temperatura. Após 14 dias, o segundo grupo foi removido da estufa, seguindo o procedimento aplicado ao $1^{\circ}$ grupo. A solução (PBS e PBS/lisozima) do $3^{\circ}$ grupo foi trocada por novas soluções e novamente acondicionada na estufa por mais 7 dias. Por fim, após 21 dias, 0 último grupo foi processado da mesma forma dos demais grupos. O cálculo da perda de massa (em percentagem) foi determinado pela equação abaixo:

$$
P M \%=\left(\frac{M_{0}-M_{f}}{M_{0}}\right) \times 100
$$

Onde: $P M \%=$ Perda de massa em percentagem, $M_{0}-$ Massa inicial, $M_{\mathrm{f}}-$ Massa final.

Tabela 2: Grupos de amostras para degradação enzimática in vitro.

\begin{tabular}{|c|c|c|c|c|c|c|}
\hline \multirow[t]{4}{*}{ ARCABOUÇO } & \multicolumn{6}{|l|}{ PERÍODO } \\
\hline & \multicolumn{2}{|l|}{7 DIAS } & \multicolumn{2}{|l|}{14 DIAS } & \multicolumn{2}{|l|}{21 DIAS } \\
\hline & PBS & $\begin{array}{l}\text { PBS + LISO- } \\
\text { ZIMA }\end{array}$ & PBS & $\begin{array}{l}\text { PBS + LISO- } \\
\text { ZIMA }\end{array}$ & PBS & PBS + LISOZIMA \\
\hline & $\begin{array}{l}N^{\circ} \text { de amos- } \\
\text { tras }\end{array}$ & $\begin{array}{l}N^{\circ} \text { de amos- } \\
\text { tras }\end{array}$ & $\begin{array}{l}N^{\circ} \text { de amos- } \\
\text { tras }\end{array}$ & $\begin{array}{l}N^{\circ} \text { de amos- } \\
\text { tras }\end{array}$ & $\begin{array}{l}\mathrm{N}^{\circ} \text { de amos- } \\
\text { tras }\end{array}$ & $\mathrm{N}^{\circ}$ de amostras \\
\hline Q & 05 & 05 & 05 & 05 & 05 & 05 \\
\hline QT & 05 & 05 & 05 & 05 & 05 & 05 \\
\hline QN & 05 & 05 & 05 & 05 & 05 & 05 \\
\hline QNT & 05 & 05 & 05 & 05 & 05 & 05 \\
\hline Subtotal & 20 & 20 & 20 & 20 & 20 & 20 \\
\hline Total & \multicolumn{6}{|l|}{120} \\
\hline
\end{tabular}

\section{RESULTADOS E DISCUSSÕES}

A partir dos cálculos realizados segundo as equações 3 e 4 e ilustrados na tabela 3, observa-se que os arcabouços reticulados apresentaram diminuição significativa $(\mathrm{p}<0,05)$ de diâmetro, volume e aumento da densidade quando comparados aos não reticulados (Figura 3). Este fato decorre, provavelmente, da ação do agente reticulante sobre os arcabouços, provocando a compactação dos mesmos.

Tabela 3: Média - $\bar{X}$ e desvio padrão - DP das massas, diâmetros, espessuras, volumes e densidades dos arcabouços de Q, QT, QN e QNT.

\begin{tabular}{|c|c|c|c|c|c|c|c|c|c|c|}
\hline \multirow{2}{*}{$\begin{array}{l}\text { ARCA- } \\
\text { BOUÇO }\end{array}$} & \multicolumn{2}{|c|}{ MASSA (g) } & \multicolumn{2}{|c|}{ Diâmetro (mm) } & \multicolumn{2}{|c|}{ Espessura (mm) } & \multicolumn{2}{|c|}{ VOLUME $\left(\mathrm{cm}^{3}\right)$} & \multicolumn{2}{|c|}{ DENSIDADE $\left(\mathrm{g} / \mathrm{cm}^{3}\right.$} \\
\hline & $\overline{\bar{X}}$ & DP & $\overline{\bar{X}}$ & DP & $\overline{\bar{X}}$ & DP & $\overline{\bar{X}}$ & DP & $\overline{\bar{X}}$ & DP \\
\hline $\mathbf{Q}$ & 0,5280 & 0,0311 & 45,32 & 0,66 & 7,54 & 0,60 & 13,99 & 0,96 & 0,04 & 0,003 \\
\hline QT & 0,6914 & 0,0896 & 34,63 & 0,67 & 7,35 & 0,52 & 6,43 & 0,40 & 0,11 & 0,014 \\
\hline QN & 0,6501 & 0,0041 & 47,90 & 0,98 & 10,98 & 0,74 & 19,17 & 1,42 & 0,03 & 0,003 \\
\hline QNT & 0,8214 & 0,0146 & 35,43 & 0,57 & 7,73 & 0,32 & 7,61 & 0,41 & 0,11 & 0,007 \\
\hline
\end{tabular}




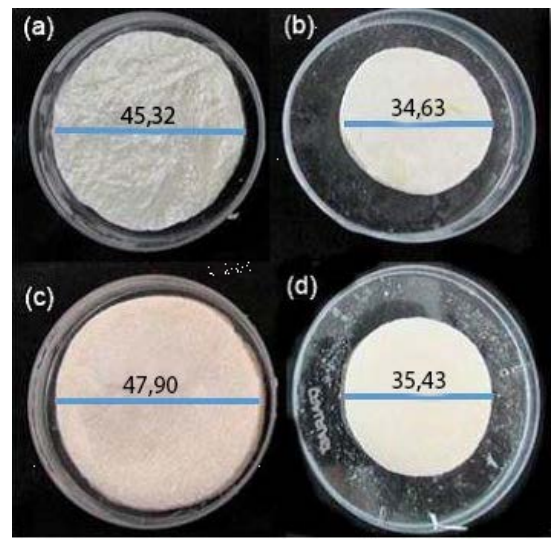

Figura 3: Medidas dos diâmetros (mm) dos arcabouços de Q (a), QT (b), QN (c) e QNT (d).

As Figuras 4 e 5 ilustram os difratogramas dos pós da quitosana, 1,4-naftoquinona, TPP e dos arcabouços de quitosana sem e com o fármaco e o agente reticulante, respectivamente.

Analisando os difratogramas, observa-se que o TPP e a 1,4-naftoquinona apresentaram picos no intervalo $2 \theta=10$ e 700 ) e $2 \theta=10$ e 600 com grau de cristalinidade de 86,81 e $60,18 \%$, respectivamente. Este fato evidencia a estrutura cristalina apresentada pelos dois compostos [7]. Entretanto, a quitosana na forma de pó apresentou dois picos largos em $2 \theta=100$ e 200 aproximadamente, grau de cristalinidade de 8,49\%, evidenciando a estrutura semicristalina do polímero [8-10].
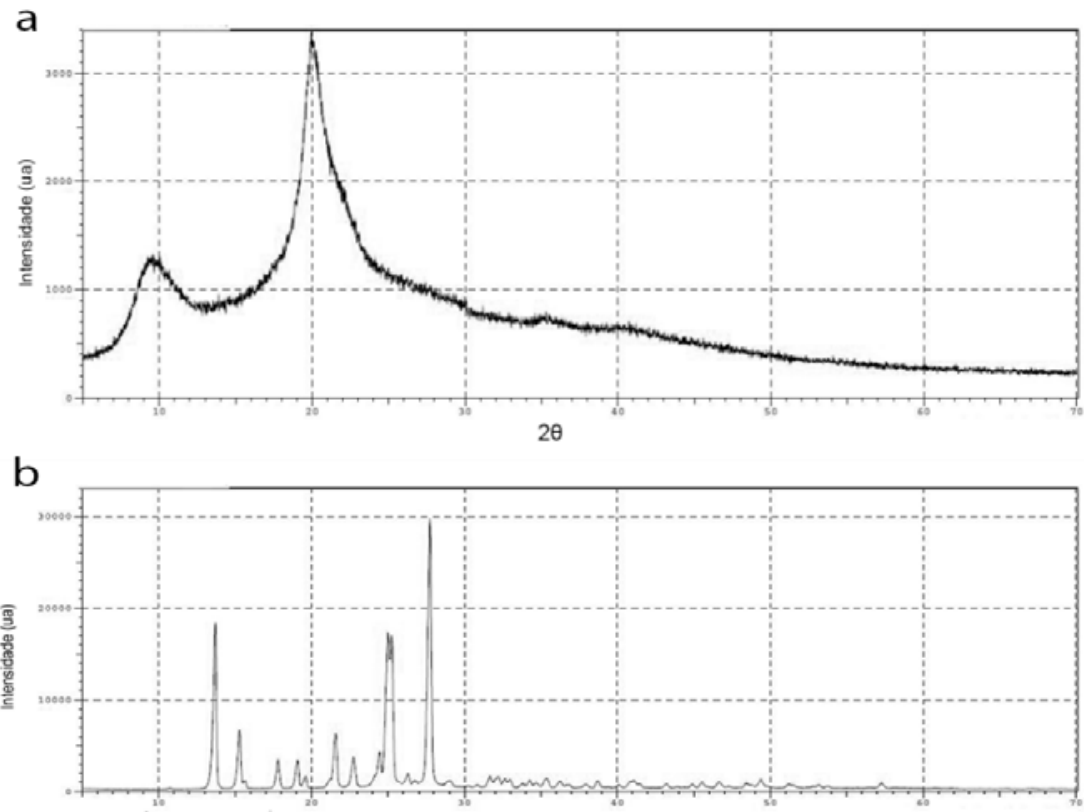

$2 \theta$

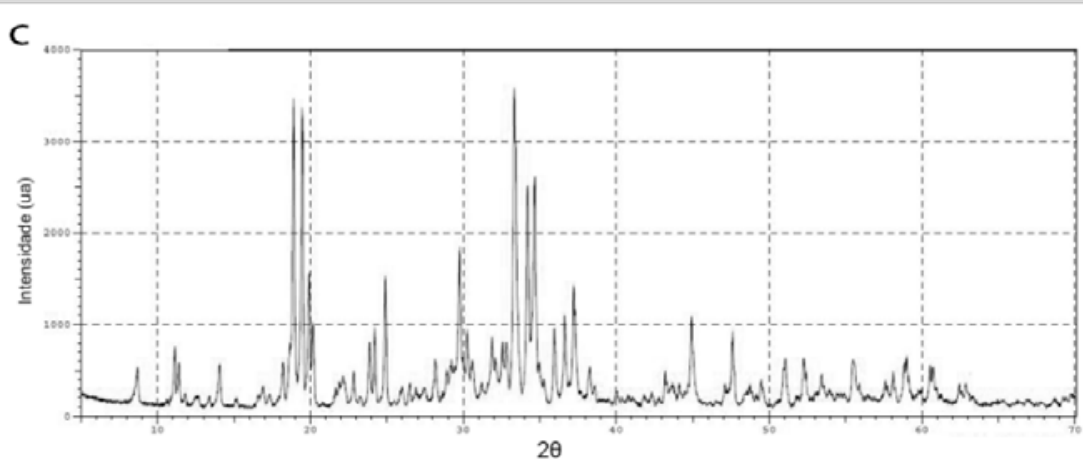

Figura 4: Difratogramas da quitosana pó (a), 1,4-naftoquinona pó (b) e TPP em pó (c) 
Com relação aos arcabouços, o de quitosana também apresentou dois picos de forma semelhante à quitosana em pó, embora o primeiro com menor intensidade e grau de cristalinidade de 4,5\%. Já o de quitosana com TPP apresentou um difratograma com um pico largo em aproximadamente $2 \theta=24^{\circ}$ e grau de cristalinidade de 2,87\%, evidenciando a diminuição da cristalinidade da quitosana ocasionada pelo agente reticulante, corroborando com a pesquisa de Laus et al. [11] que trabalhou com microesferas de quitosana reticulada com TPP e Fook [12] que trabalhou com o polímero reticulado com glutaraldeido e procianidinas.

$\mathrm{O}$ arcabouço de quitosana com 1,4-naftoquinona apresentou dois picos largos em $2 \theta=10$ e $20^{\circ}$ (Figura 8) menos intensos do observado no arcabouço de quitosana e grau de cristalinidade de 2,04 \%, demonstrando a influência do fármaco na matriz polimérica. Por fim, o conjunto quitosana/TPP/1,4-naftoquinona evidenciou um pico em $2 \theta=20^{\circ}$ e grau de cristalinidade de 2,54\% (Figura 9), indicando uma possível competição entre o fármaco e o TPP pelos mesmos sítios de ligação. Estes dados são relevantes uma vez que a velocidade de degradação enzimática da quitosana é inversamente proporcional ao seu grau de cristalinidade [2, 3]. O grau de cristalinidade de todos os materiais foi calculado automaticamente pelo software que acompanha o Difratômetro de Raios X.

a

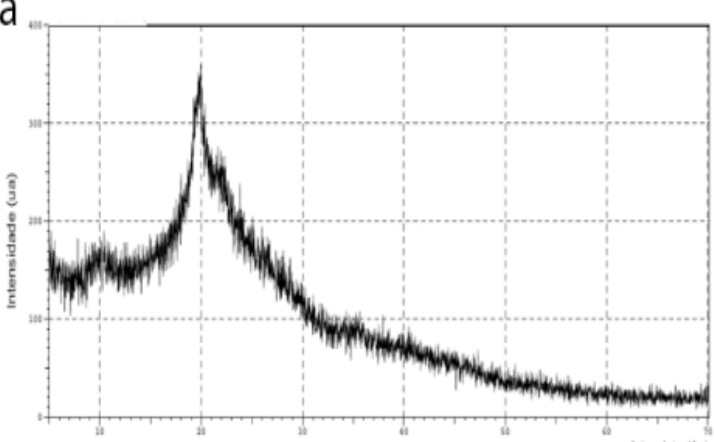

C

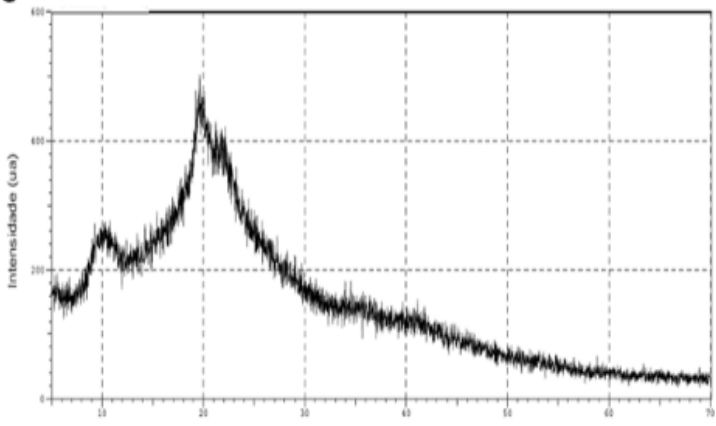

b

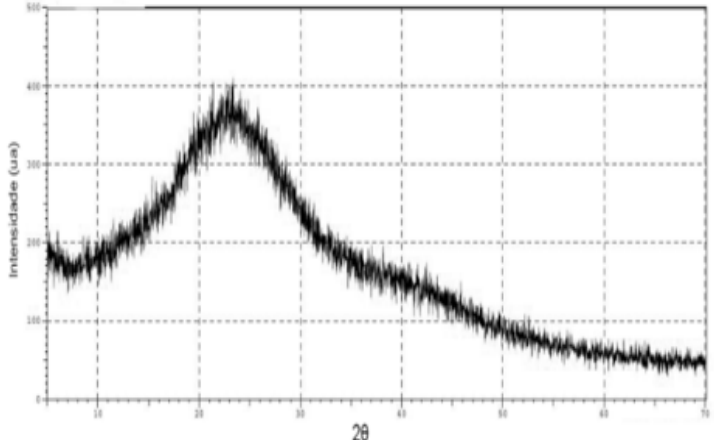

d

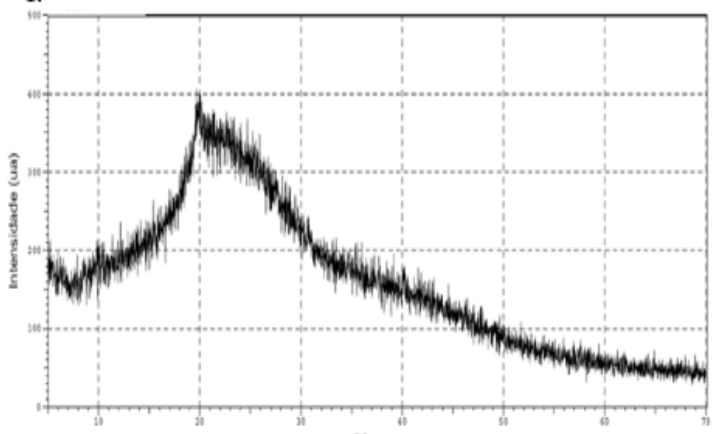

Figura 5: Difratograma dos arcabouços de quitosana (a), quitosana com tripolifosfato(b), quitosana com 1,4naftoquinona (c) e quitosana com tripolifosfato e 1,4-naftoquinona (d)

As micrografias das superfícies e cortes transversais dos arcabouços são observadas nas Figuras de 6 a 9, onde se evidencia uma estrutura porosa na superfície e uma região transversal lamelar com a mesma característica porosa em todas as micrografias, indicando a presença de poros intercomunicantes. Estas observações estão de acordo com os trabalhos de Fook [12], Azevedo [9] e Fávere [13].

Abaixo de cada micrografia está ilustrado o gráfico de barras com a composição química elementar de alguns pontos da superfície e região de corte de cada arcabouço. 


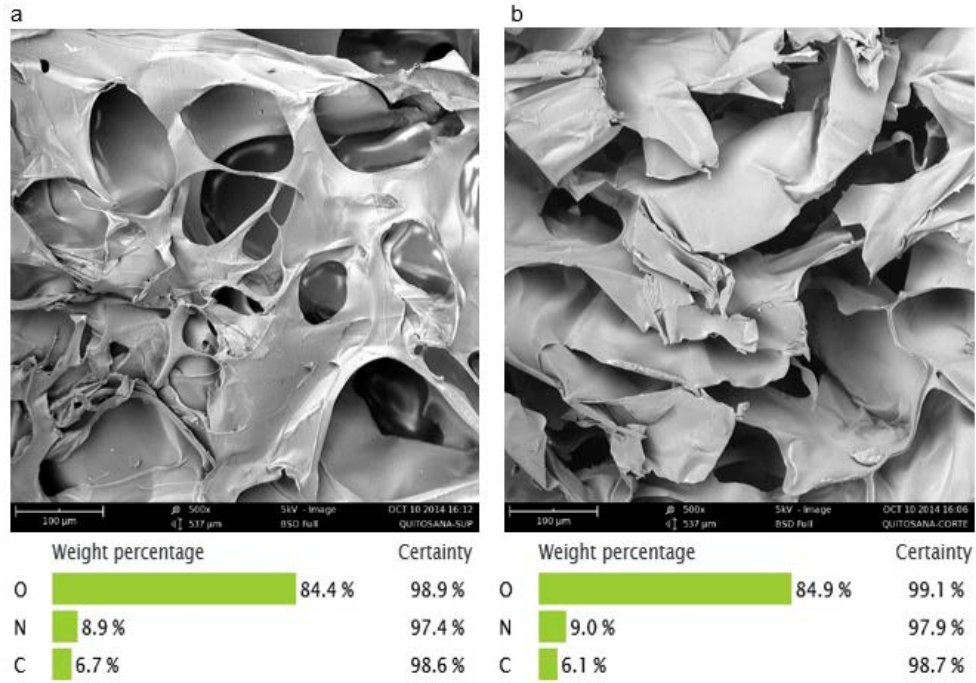

Figura 6: Micrografia Eletrônica da Superfície (a), Corte (b) e EDS do Arcabouço de Quitosana
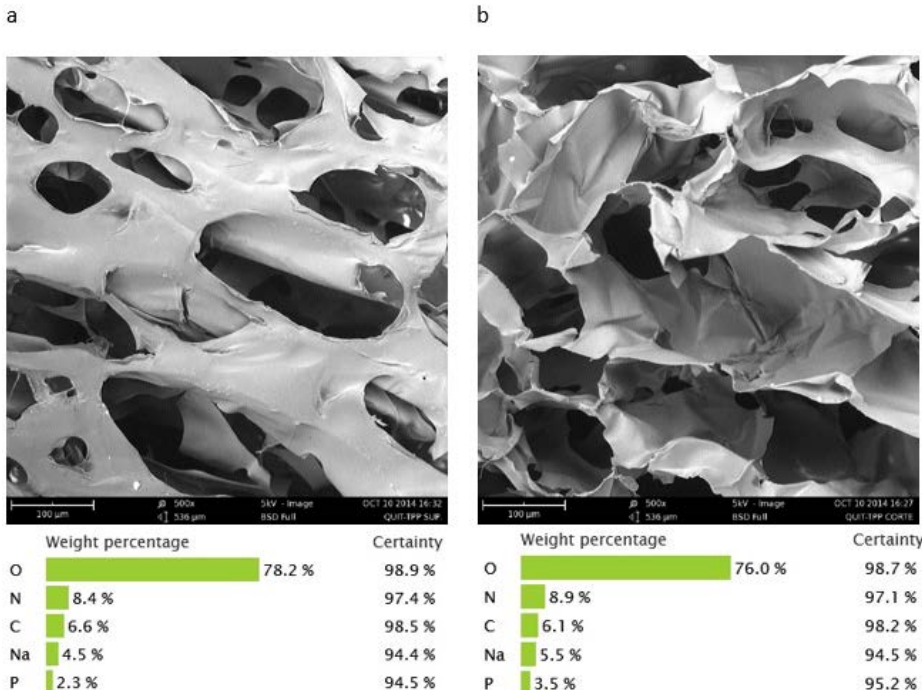

Figura 7: Micrografia Eletrônica da Superfície (a), Corte (b) e EDS do Arcabouço de Quitosana com TPP
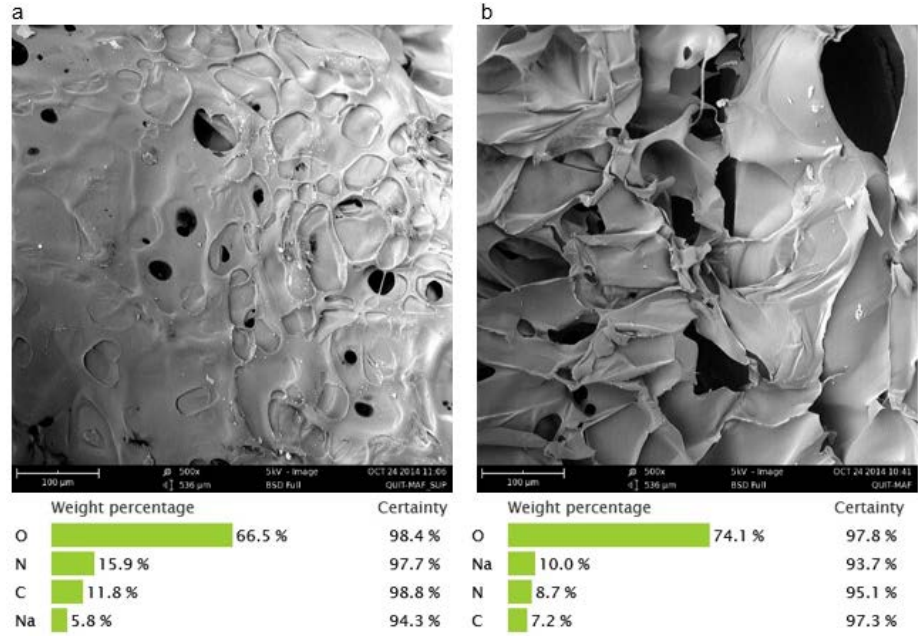

Figura 8: Micrografia Eletrônica da Superfície (a), Corte (b) e EDS do Arcabouço de Quitosana com 1,4- naftoquinona 

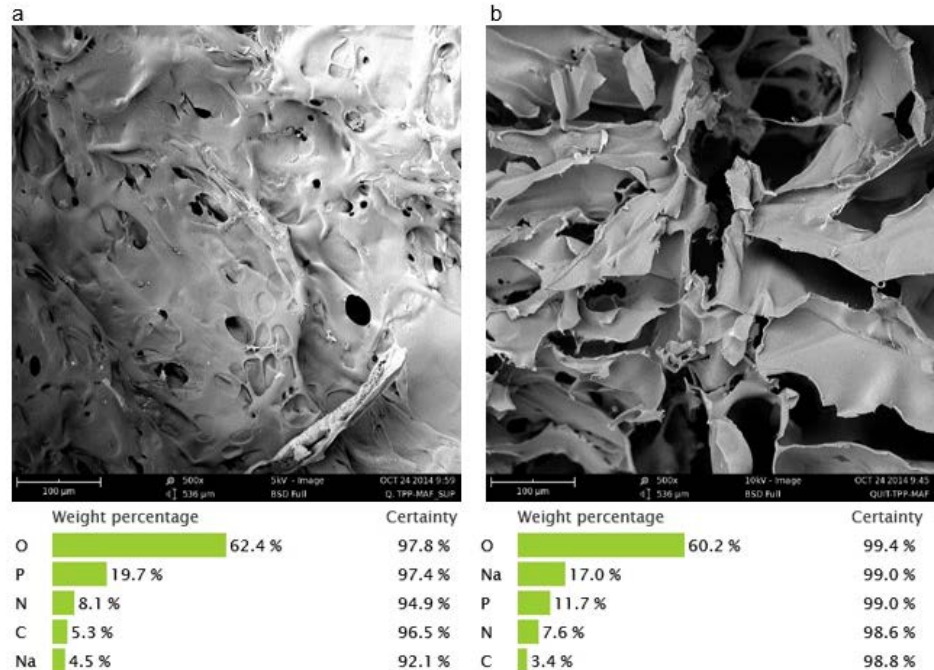

Figura 9: Micrografia Eletrônica da Superfície (a), Corte (b) e EDS do Arcabouço de Quitosana com 1,4-naftoquinona e TPP

A porosidade evidenciada em todos os arcabouços é de grande importância para um sistema de liberação controlada de fármacos, pois, segundo Fávere [13], permite a penetração de fluidos biológicos, facilitando a difusão dos fármacos para o meio.

A caracterização por EDS demonstrou a presença dos elementos químicos presentes na quitosana (O, $\mathrm{C}$, e N) e, no caso dos arcabouços reticulados, a presença do fósforo, comprovando a presença do TPP. Outro dado relevante é um maior percentual de oxigênio na região de corte dos arcabouços com 1,4-naftoquinona, indicando a incorporação do fármaco na matriz. Entretanto, em alguns arcabouços, observou-se a presença do sódio, elemento que não faz parte da estrutura química da quitosana nem da 1,4-naftoquinona, decorrente, possivelmente, da presença de resíduos do agente neutralizador.

Na Figura 10, observa-se o grau de intumescimento das amostras dos arcabouços. Verificou-se que houve um ganho de massa de aproximadamente 13, 8, 12 e 9 vezes nos arcabouços de quitosana, quitosana e TPP, quitosana com 1,4-Naftoquinona e quitosana + 1,4-naftoquinona e TPP, respectivamente, indicando uma alta capacidade de absorção por todos os arcabouços. Este fato decorreu provavelmente da penetração do líquido nos arcabouços porosos e da interação da água (através de ligações de hidrogênio) com pontos reativos $(-\mathrm{NH} 3+$, $\mathrm{NH} 2$ e - $\mathrm{OH})$. Os grupos -NH3+ estão presentes, principalmente, nas unidades GlcN da quitosana com $\mathrm{pH}$ inferior a 7,2 [18].

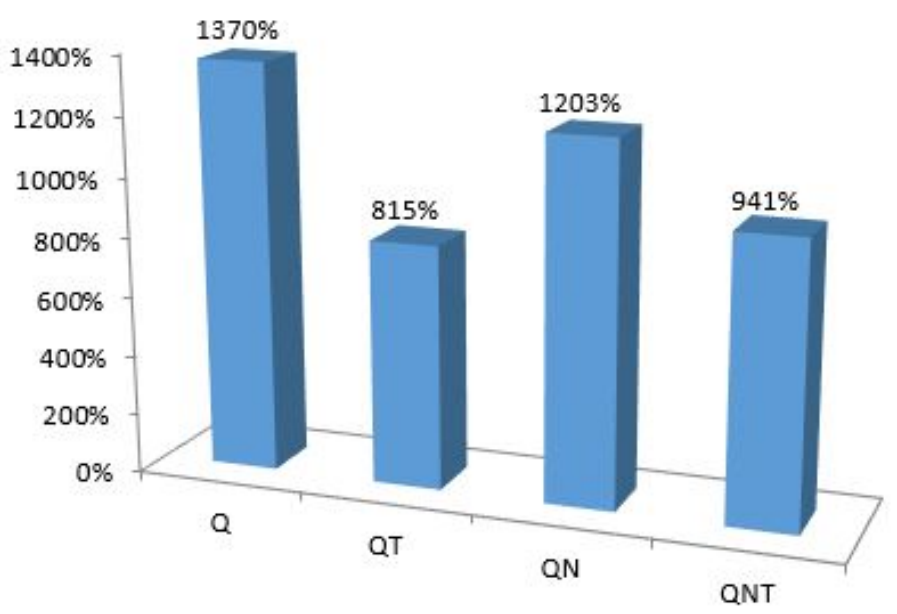

Figura 10: Grau de intumescimento dos arcabouços de Q, QT, QN e QNT

O menor intumescimento observado em QT e QNT decorreu da possível interação do agente reticu- 
lante e do fármaco competindo com a água pelos mesmos sítios reativos. Já na comparação entre QT e QNT, o maior intumescimento do arcabouço contendo o fármaco deve-se provavelmente a competição entre o mesmo e o agente reticulante e a interação de sítios reativos da 1,4-naftoquinona com moléculas de água. Resultados semelhantes foram obtidos por Fidéles [14], Fook [12], Jiankang et al. [15] e Oliveira [16].

Comparando-se as diferenças entre a massa seca e intumescida para cada arcabouço, o resultado foi altamente significativo $(p<0,001)$. Com relação à $Q$ e $Q T$, a diferença foi significativa $(p<0,05)$. Já entre $Q$ e QN intumescidos, a diferença não foi significante $(\mathrm{p}>0,05)$, sendo extremamente significativa entre QT e QNT.

A degradação dos arcabouços em solução de PBS e PBS/lisozima em 7, 14 e 21 dias está descrita na Tabela 4, onde se observou um ganho de massa decrescente nos arcabouços de Q e QN. Este fato provavelmente decorreu da lavagem com água destilada ter sido insuficiente, principalmente do primeiro grupo (após 7 dias), para remoção do sal, precipitação do mesmo nas amostras e, portanto, ganho de massa. Também se observou perda de massa nos arcabouços QT e QNT mesmo na solução contendo apenas PBS, possivelmente em virtude das modificações do pH do meio que oscilou de 7.4 no início dos ensaios até 7.08 no final. Resultado semelhante foi obtido por Oliveira et al. [17].

Tabela 4: Média - $\bar{X}$ (\%) e desvio padrão - DP para biodegradação enzimática em solução de PBS e PBS/lisozima dos arcabouços Q, QT, QN, QNT nos intervalos 7, 14, 21 dias.

\begin{tabular}{|c|c|c|c|c|c|c|c|c|c|c|c|c|}
\hline \multirow[t]{4}{*}{ Arcabouços } & \multicolumn{6}{|c|}{ PERCENTAGEM DE PERDA DE MASSA } & \multicolumn{6}{|c|}{ PERCENTAGEM DE PERDA DE MASSA } \\
\hline & \multicolumn{6}{|l|}{ PBS } & \multicolumn{6}{|c|}{ PBS + Lisozima } \\
\hline & \multicolumn{2}{|c|}{7 Dias } & \multicolumn{2}{|c|}{14 Dias } & \multicolumn{2}{|c|}{21 Dias } & \multicolumn{2}{|c|}{7 Dias } & \multicolumn{2}{|c|}{14 Dias } & \multicolumn{2}{|c|}{21 Dias } \\
\hline & $\bar{X}$ & DP & $\overline{\boldsymbol{X}}$ & DP & $\overline{\boldsymbol{X}}$ & DP & $\bar{X}$ & DP & & DP & $\bar{X}$ & DP \\
\hline Q & $-22^{*}$ & 0,0009 & $-7^{*}$ & 0,0048 & $-2^{*}$ & 0,0022 & 22 & 0,0054 & 25 & 0,0048 & 41 & 0,0045 \\
\hline QT & 3 & 0,0050 & 6 & 0,0027 & 17 & 0,0060 & 43 & 0,0036 & 79 & 0,0039 & 74 & 0,0017 \\
\hline QN & $-28^{*}$ & 0,0017 & $-17^{*}$ & 0,0024 & $-14^{*}$ & 0,0025 & 11 & 0,0050 & 18 & 0,0077 & 5 & 0,0025 \\
\hline QNT & 3 & 0,0045 & 6 & 0,0020 & 13 & 0,0036 & 43 & 0,0037 & 77 & 0,0034 & 67 & 0,0049 \\
\hline
\end{tabular}

*Valores negativos significam ganho de massa.

Todos os arcabouços imersos em solução com lisozima apresentaram maior perda de massa em 7, 14 e 21 dias do que aqueles em solução com apenas PBS. Nota-se, ainda, os arcabouços reticulados apresentaram maiores valores percentuais de perda de massa. A causa provável foi à diminuição da cristalinidade do polímero provocada pelo agente reticulante, demonstrada nos ensaios de DRX e grau de intumescimento. O ganho de massa apresentado por alguns arcabouços em PBS deveu-se, possivelmente, à precipitação de sais de PBS que não foi possível ser removido pelas lavagens com água destilada, descrita acima. Resultado semelhante foi observado por Fernandes [21]. Entretanto, nos grupos referentes aos intervalos de 14 e 21 dias, o processo de lavagem foi intensificado (aumento do número de lavagens), resolvendo parcialmente o problema, já que o ganho de massa foi menor. A maior velocidade de degradação provocada pela reticulação, decorrente do menor grau de cristalinidade provocada pelo agente reticulante $[3,11]$ é um fator importante uma vez que, variando esta taxa, é possível controlar a duração do sistema de liberação do fármaco no organismo, bem como a liberação do próprio fármaco.

Embora a velocidade de degradação dos arcabouços reticulados confeccionados nesse trabalho tenha sido maior do que os não reticulados, Holanda [22, 23] observou comportamento inverso em membranas incorporadas com insulina e reticuladas com TPP.

\section{CONCLUSÕES}

- O estudo morfológico dos arcabouços realizado por MEV revelou a formação de uma estrutura tridimensional com poros interconectados;

- Através da técnica de EDS, pode-se confirmar a presença dos elementos sódio, nitrogênio, carbono, fósforo, oxigênio e nitrogênio, nos arcabouços produzidos. 
- A reticulação dos arcabouços aumentou a velocidade de degradação.

- Houve formação de arcabouços porosos, com propriedades morfológicas e físico-químicas que podem contribuir para carrear fármacos antineoplásicos cuja taxa de degradação pode ser controlada pela reticulação dos mesmos.

- A incorporação do fármaco pelo arcabouço foi confirmada pelo DRX, Grau de Intumescimento e EDS.

\section{BIBLIOGRAFIA}

[1] FRÁGUAS, R. M., ROCHA, D, A., QUEIROZ,E.R. et al., "Caracterização química e efeito cicatrizante de quitosana, com baixos valores de massa molar e grau de acetilação, em lesões cutâneas”, Polímeros, v. 25, n. 2, pp. 205-2011, 2015

[2] PONCIANO, J. J., Desenvolvimento de membranas bioabsorvíveis com variável nível de orientação molecular para aplicação como biomaterial. Dissertação de M.Sc., PPGCEMat., UFCG, Campina Grande, PB, Brasil, 2010.

[3] LARANJEIRA, M. C., FÁVERE, V. C., "Quitosana: biopolimero funcional com potencial industrial biomédico”, Química Nova, v.32, n.3, 2009.

[4] KAYASHIMA, T., MORI, M., YOSHIDA, H., et al., "1,4-Naphthoquinone is a potent inhibitor of human cancer cell growth and angiogenesis”. Cancer Letters, v. 278, n. 1, pp.34-40, June, 2009.

[5] GUINESI, L. S., ESTEVES, A. A., CAVALHEIRO, E. T. G., "Adsorção de íons cobre (II) pela quitosana usando coluna em sistema sob fluxo hidrodinâmico”, Química Nova, v.30, n.4, pp. 809-814, Jul/Aug. 2007.

[6] KUMAR, V., ABBAS, K. A., FAUSTO, N., et al., Patologia -Bases Patológicas das Doenças., 8 ed, Rio de Janeiro, Elsevier, 2010.

[7] BOU, E., ORTZM.J., SÁNCHES, E., et al., "Controle de Qualidade dos Tripolifosfatos Sódicos Empregados na Fabricação de Engobes e Esmaltes”, Cerâmica Industrial, v.5 n.4, pp. 13-20 agosto, 2000.

[8] MANSUR, H. S., COSTA, E. S., "Preparação e Caracterização de Blendas de Quitosana/poli (Álcool Vinílico) Reticuladas Quimicamente com Glutaraldeído para Aplicação em Engenharia de Tecido”, Química Nova, v.31, n.6, pp. 1460-1466, 2008.

[9] AZEVEDO, V. V. C., CHAVESS. A., BEZERRA D. C., et al., "Quitina e Quitosana: aplicações como biomateriais”, Revista Eletrônica de Materiais e Processos, v.2, n.3, pp. 27-34, Dez, 2007.

[10] SOUZA, K. S., O uso de polissacarídeo natural quitosana quimicamente modificado na remoção de cátions e termoquímica de interação na interface sólido/llquido., Tese de D.Sc., UEC, Instituto de Química, São Paulo, 2009.

[11] LAUS, R., LARANJEIRA, M. C. M., MARTINS, A. O., et al., "Microesfera de quitosana reticuladas com tripolifosfato utilizadas para remoção de acidez, ferro (III) e manganês (II) de águas contaminadas pela mineração de carvão”, Química Nova, v.29, n.1, Jan/Fev, 2006.

[12] FOOK, A. C. B. M., Produção e caracterização de arcabouços compósitos HA/Biopolímero para engenharia de tecidos., Tese de D.Sc., PPGCEMat., UFCG, Campina Grande, PB, 2012.

[13] FÁVERE, V. T., LARANJEIRA, M. C. M., "Quitosana: biopolímero funcional com potencial industrial biomédico”, Quimica Nova, v. 32, n.3, pp. 672-678, 2009.

[14] FIDÉLES, T. B., Desenvolvimento de scaffolds de quitosana para aplicação na engenharia de tecidos. Tese de D.Sc., PPGCEMat., UFCG, Campina Grande, PB, 2014.

[15] JIANKANG, H., DICHEN, L., YAXIONG, L., et al., "Preparation of chitosan-gelatin hybrid scaffolds with well-organized microstructures for hepatic tissue engineering”, Acta Biomaterialia, v.5, n.1, pp. 453461, Jan, 2009.

[16] OLIVEIRA, A. P. R., Desenvolvimento de membranas de gelatina/quitosana e o estudo do processo de reticulação. Dissertação de M.Sc., EESC/FMRP/IQSC, São Carlos, SP. 2013

[17] OLIVEIRA, R. A., BARBOZA, P. A., CARDOSO, M.J.B., et al., "Síntese e caracterização de Compósito Quitosana Extraído de Casca de Ovo para possíveis Aplicações como Curativo”, In: Encontro Nacional de Educação, ciência e Tecnologia/UEPB, Campina Grande, PB, Nov, 2012.

[18] GONÇALVES, A. A., ARAÚJO, R. M., "Diferentes estratégias para a Reticulação de quitosana”, Química Nova, v. 34, n. 7, pp. 1215-1233, 2011. 
[19] ASTM International: F1635-04 Standard Test Method for in vitro Degradation Testing of Hydrolytically Degradable Polymer Resins and Fabricated Forms for Surgical Implants. 2009.

[20] ASTM International: F2103-01 Standard Guide for Characterization and Testing of Chitosan Salts as Starting Materials Intended for Use in Biomedical and Tissue-Engineered Medical Product Applications, 2007.

[21] FERNANDES, L. L., Produção e caracterização de membranas de quitosana e quitosana com sulfato de condroitina para aplicações biomédicas , Monografia., DEPARTAMENTO DE ENGENHARIA METALURGICA E DE MATERIAIS/UFRJ, Rio de Janeiro, RJ, Brasil, 2009.

[22] HOLANDA, L. A., Membranas de quitosana para usos em sistema de liberação controlada de Insulina. Tese de D.Sc., PPGEP/UFCG, Campina Grande, PB, Brasil, 2011.

[23] HOLANDA, L. A., FOOK, M. V. L., RAMDAYAL, S. "Preparation and Characterization of ChitosanInsulin-Tripolyphosphate Membrane for Controlled Drug Release: Effect of Cross Linking Agent”, Journal of Biomaterials and Nanobiotechnology, v. 5, pp. 211-219, 2014. 
ERRATA

Na página 129 , Onde se lia:

"Rosemberg Cardoso Barbosa"

Leia-se

"Rossemberg Cardoso Barbosa"

Revista Scielo(2016) 21(1):129-140 